\title{
CONTROL COMO CAUSAL DE UNA OFERTA PÚBLICA DE ADQUISICIÓN DE ACCIONES OBLIGATORIA Y SU REGULACIÓN EN CHILE
}

\author{
MARIO VALDERRAMA V. \\ Universidad de Chile
}

\begin{abstract}
RESUMEN: Este estudio define el control corporativo para efectos de la aplicación del artículo 199 a) de la Ley de Mercado de Valores, analizando normativa, doctrina y jurisprudencia relativa a la materia, para finalmente entregar una visión crítica de la regulación chilena de Oferta Pública de Adquisición de Acciones.
\end{abstract}

Palabras Clave: Control corporativo, toma de control, oferta pública de acciones.

ABSTRACT: The following essay defines corporate control according to Article 199 section (a). Specifically, the essay focuses on the Chilean Securities Law including an analysis of norms, doctrines, and jurisprudence, reviewing the Chilean tender offer regulation.

Key words: Corporate control, control takeover, tender offer.

\section{INTRODUCCIÓN}

Con la Ley No 19.705, de 20 de diciembre del año 2000, que regula la oferta pública de adquisición de acciones (OPA), el gobierno de la época buscó impulsar la modernización del mercado de valores chileno, a través de incrementar los niveles de protección a los accionistas minoritarios, estableciendo "un sistema orgánico y armónico que solucione las inequidades que el mercado, a través de las leyes económicas de oferta y demanda, no ha podido superar" ${ }^{\prime}$.

Para lograr este propósito se estableció, entre otras medidas, un régimen obligatorio de OPA, en el caso de tomas de control, donde se pague un precio sustancialmente superior al de mercado, denominado premio de control.

$\mathrm{Al}$ respecto, en la tramitación de dicho proyecto no existió debate sobre un concepto esencial para hacer aplicable el procedimiento obligatorio de OPA: el concepto de control. Tanto es así que, en la mayoría de la tramitación de la referida ley, ni siquiera fue contemplado como causal para gatillar dicho procedimiento sino que este procedía por la adquisición de ciertos porcentajes del capital accionario (20\% y en etapas posteriores de su tramitación

\footnotetext{
Abogado, Licenciado en Ciencias Jurídicas y Sociales por la Universidad de Chile (2006). Profesor de Taller de Memoria de Mercado de Valores en la Facultad de Derecho de la Universidad de Chile (2008 a la fecha).

1 Biblioteca del Congreso Nacional. Historia Fidedigna de la Ley No 19.705, que Regula las Ofertas Públicas de Adquisición de Acciones (OPAS) y Establece Régimen de Gobiernos Corporativos. Santiago, Chile: Congreso Nacional, p. 98.
} 
alcanzó al 30\%). Semejante omisión ha sido integrada por parte de la doctrina y por la jurisprudencia administrativa de la Superintendencia de Valores y Seguros (SVS) asimilando, sin más, control corporativo con el concepto legal de controlador establecido en la Ley No. 18.045, Ley de Mercado de Valores (LMV), lo cual es un error, según explicaré latamente durante el desarrollo del presente trabajo.

Asimismo, la segunda parte de este trabajo se enfoca en realizar un análisis crítico de la OPA, por estimar que este vulnera los principios matrices de la sociedad de capital, al establecer implícitamente un deber para el accionista controlador de resguardar el retorno de la inversión de los demás accionistas, aplicando esta legislación criterios redistributivos, sin considerar los derechos de propiedad existentes de aquellas personas que tienen el control de una compañía y se ven entorpecido e, incluso, impedidos de enajenarlo debido al incremento de los costos para posibles oferentes.

\section{CONCEPTO DE CONTROL: ESTADO DE LA CUESTIÓN EN LA DOCTRINA NACIONAL}

Determinar que es el control corporativo de una sociedad anónima acarrea consecuencias jurídicas gravitantes en la LMV y la Ley No. 18.046 sobre Sociedades Anónimas (LSA), entre ellas, determina la aplicación obligatoria de una OPA, según el artículo 199 letra a) de la LMV. A pesar de ello, no existe una definición legal específica ni tampoco existe consenso respecto de su significado exacto en la literatura nacional, lo cual, por cierto, lo convierte en un concepto controvertido. Al respecto, pueden distinguirse, a lo menos, las siguientes posiciones:

\subsection{CONTROL CORPORATIVO COMO UN HECHO}

El primer intento de explicar este concepto en Chile sostuvo que "al hablar de dominio y control me refiero a una situación real de poder de disponibilidad de medios, de cualquier clase, jurídicos, económicos, políticos, culturales, etc.; para mandar, organizar y disponer" 2 . En el mismo sentido, fue definido posteriormente como "la facultad de tomar las decisiones estratégicas y operativas de una empresa, las que afectan sus flujos presentes y futuros"3.

Según se aprecia de lo transcrito, esta noción se vinculó inicialmente solo con las circunstancias fácticas que permitían ejercer el control de una sociedad. Como es lógico, este tipo de control de hecho, no guarda vínculo alguno, ni se ajusta a ningún criterio normativo

\footnotetext{
2 VIAL, Felipe. "Responsabilidad civil extracontractual del controlador de sociedades", en: Revista de Derecho Económico, No. 68-69, p. 107. Santiago, Chile: Departamento de Derecho Económico, Facultad de Derecho U. de Chile, 1987.

3 CABReRA, Ángel; et al. Regulación de las transferencias de control corporativo: Discusión teórica e implementación empirica. Santiago, Chile: Serie documentos de discusión. Superintendencia de Valores y Seguros, 2000, p. 35.
} 
establecido en LSA o la LMV y, de esta forma, tiene la evidente desventaja que no permite dar certeza de su contenido y, por supuesto, de su titularidad. Así, por ejemplo, podría, bajo este concepto, ser titular del control un representante de tenedores de bonos, bajo un contrato de emisión en que la compañía se obligue a solicitar su autorización para tomar decisiones propias de la junta de accionistas, según lo dispuesto en el artículo 111 de la LMV; o un gerente general de una sociedad dedicada a la biotecnología, cuya gestión es totalmente respaldada por el directorio, y los accionistas carecen del know how para monitorear la administración del mencionado gerente. En estos casos, ¿tiene el citado representante o el gerente general el control del emisor? Pese que a la luz de las definiciones transcritas la respuesta podría ser positiva, como analizaremos más adelante, la respuesta es definitivamente no.

\subsection{CONTROL COMO SINÓNIMO DE CONTROLADOR}

La posición más influyente en Chile asimila, sin más, el concepto de control al concepto de controlador de los artículos 97 y 99 de la LMV4, el señalar que: "Desde el punto de vista legal, el concepto de control ha recibido una expresa consagración legal"5 para pasar a continuación a realizar una descripción de los mencionados artículos, agregando a continuación que:

"De lo anterior se sigue que lo esencial al concepto legal de controlador estriba en la facultad de tomar decisiones estratégicas y operativas de una empresa, en cuanto ello solo es posible [el subrayado es mío] si se tiene la mayoría en los órganos de decisión o sin tener esa mayoría, se tiene igualmente la capacidad de influir decisivamente en los órganos de administración de la compañía mediante acuerdos de actuación conjunta"6.

Agrega la mencionada posición que: "Creemos nosotros que las hipótesis que se formulan en las dos letras del precepto citado [artículo 97 de la LMV] dan cuenta de un único

\footnotetext{
4 El mencionado artículo establece: "Artículo 97. Es controlador de una sociedad toda persona o grupo de personas con acuerdo de actuación conjunta que, directamente o a través de otras personas naturales o jurídicas, participa en su propiedad y tiene poder para realizar alguna de las siguientes actuaciones: a) Asegurar la mayoría de votos en las juntas de accionistas y elegir a la mayoría de los directores tratándose de sociedades anónimas, o asegurar la mayoría de votos en las asambleas o reuniones de sus miembros y designar al administrador o representante legal o a la mayoría de ellos, en otro tipo de sociedades, o b) Influir decisivamente en la administración de la sociedad. Cuando un grupo de personas tiene acuerdo de actuación conjunta para ejercer alguno de los poderes señalados en las letras anteriores, cada una de ellas se denominará miembro del controlador...”. Por su parte, el artículo 99 agrega: "Artículo 99. Se entenderá que influye decisivamente en la administración o en la gestión de una sociedad toda persona, o grupo de personas con acuerdo de actuación conjunta, que, directamente o a través de otras personas naturales o jurídicas, controla al menos un $25 \%$ del capital con derecho a voto de la sociedad...”.

5 PFEFFER, Francisco. "Nuevas regulaciones en las tomas de control y oferta pública de adquisición de acciones", en: Revista Chilena de Derecho, vol. 28, p. 122. Santiago, Chile: Pontificia Universidad Católica de Chile, 2001.

$6 \quad$ Ibid., p. 124.
} 
concepto de control. Se trata de un control legal, dado que es el propio legislador quien describe las hipótesis que conducen a tal concepto"7.

Asimismo, se ha sugerido que se puede "distinguir los conceptos de control legal precario o sin poder de bloqueo y de control legal efectivo, absoluto o con poder de bloqueo. Se tiene el control legal precario o sin poder de bloqueo en la hipótesis del artículo 99 de la LMV, esto es, con la propiedad del 25\% de las acciones de la sociedad siempre que no exista otro accionista con un porcentaje igual o superior o con la propiedad de entre el $25 \%$ hasta el $40 \%$ de las acciones siempre que el porcentaje controlado sea superior a la suma de las participaciones de los otros accionistas con más del 5\% del capital social. En esta hipótesis la propiedad de las acciones no es garantía de un control efectivo de la sociedad. En cambio, se tiene el control legal efectivo o con poder de bloqueo, cuando se tiene propiedad sobre la mayoría suficiente de acciones como para asegurar los votos en la junta y elegir a la mayoría del Directorio. En esta hipótesis sí que existe un control efectivo de la sociedad. El control legal precario no es sinónimo de control efectivo. Conforme con lo anterior, el concepto de controlador se construye siempre en base a la propiedad sobre acciones" ${ }^{\text {. }}$.

En relación a la posición recién enunciada puede señalarse que adolece de cierta ambivalencia en su formulación, ya que por una parte, señala que el concepto de control es sinónimo de controlador pero a su vez, indica que es controlador quien pueda tomar decisiones estratégicas y operativas de una empresa, retornando a la noción de control de hecho, introduciendo con ello la dosis de incertidumbre enunciada anteriormente.

Adicionalmente, esta posición señala que tal poder de tomar decisiones estratégicas dentro de una compañía se puede lograr, exclusivamente, a través de cumplir con los requisitos establecidos en el artículo 97 y 99 de la LMV, lo cual, como veremos más adelante, no es efectivo.

En el mismo sentido, cabe a su vez señalar que, el tenor literal de los artículos 97 y 99 de la LMV es bastante claro en señalar cuáles son los requisitos exigibles a efectos de calificar como tal al controlador. Se es controlador si: (a) se participa directa o indirectamente en la propiedad del emisor; (b) asegurando la mayoría de las acciones con derecho a voto en las

\footnotetext{
Ibid., p. 124 .

8 PFEFFER, Francisco. "El concepto de control societario, la administración de la sociedad anónima, los conflictos de interés y la potestad punitiva de la Superintendencia de Valores y Seguros en el contexto del denominado 'Caso Chispas' ”. <En línea> [consultado el 20 de diciembre de 2007] <http://www.pfeffer.cl/publicaciones/doc/EL\%20CONCEPTO\%20DE\%20CONTROL\%20SOCIETARIO.pdf>, p. 11. Desde mi punto de vista, esta clasificación no es precisa ya que el control legal precario se basa en la propiedad de acciones logrando el umbral mínimo para enmarcarse en la definición legal de controlador y la palabra precario en un sentido estrictamente jurídico es una cuestión de hecho tolerada o ignorada por quien tiene derecho a reclamar de aquella. En ese sentido es tomado en otras normas de nuestro ordenamiento, como en el artículo 2195 del Código Civil que establece: "Constituye también precario la tenencia de una cosa ajena, sin previo contrato y por ignorancia o mera tolerancia del dueño". También en PfEFFER, Francisco "El concepto de control societario, la administración de la sociedad anónima, los conflictos de interés y la potestad punitiva de la Superintendencia de Valores y Seguros en el contexto del denominado "Caso Chispas”, en: Revista Chilena de Derecho, vol. 32, No. 3, pp. 501-537, p. 511. Santiago, Chile: Pontifica Universidad Católica de Chile, 2005.
} 
juntas de accionistas nombrando a la mayoría del directorio; o (c) controlar, al menos, un $25 \%$ de las acciones emitidas con derecho a voto (salvo que concurra alguna excepción del artículo 99 de la LMV).

En base a las disposiciones indicadas, la única forma de asegurar la mayoría de los votos para una junta de accionistas (requisito signado con la letra b del párrafo precedente) es ser propietario de más del 50\% de las acciones emitidas con derecho a voto, ya que la palabra asegurar obliga al intérprete a realizar un análisis ex ante en abstracto respecto de que porcentaje de acciones necesarias para contar con dicha facultad, lo que, por cierto, solo ocurre si se tiene más del 50\% de los votos. Sería absurdo señalar que con menos de dicho porcentaje puede asegurar la mayoría, ya que siempre existe la posibilidad de coalición de los demás accionistas para bloquear a cualquier accionistas mayoritario, lo que, por sí solo, basta para no permitir asegurar la mayoría en una junta de accionistas.

Cabe hacer notar, además, lo caprichoso de los porcentajes establecidos en el artículo 99 de la LMV. Veamos, si un accionista tiene un 24\% de las acciones emitidas con derecho a voto, pudiendo nombrar a 3 de 5 directores de una sociedad anónima abierta, en que ninguno de los restantes accionistas alcanza el 0,01\% de las acciones, bajo este concepto, ¿es controlador? Veamos, aquel no tiene más del $50 \%$ de las acciones emitidas con derecho a voto, por lo tanto, no le es aplicable la letra a) del artículo 97 ya que no puede asegurar la mayoría de los votos en la junta de accionista; tampoco tiene influencia decisiva en la administración ya que no alcanza el 25\% que exige el artículo 99 de la LMV. Ahora, el mencionado accionista ¿es titular del control? Según esta tesis no, pero, como veremos más adelante, parece evidente que sí. Esta inconsistencia es problemática en sociedades anónimas de propiedad atomizada.

Como quedó de manifiesto, la LMV no contempla ni cercanamente toda la gama de situaciones que se presentan dentro de una sociedad anónima en relación a las tomas de control, ni menos aun las perfila y delimita, y aquello es lógico, ya que dicha disposición fue estableci$\mathrm{da}$, como detallaremos con mayor profundidad más adelante, para develar el denominado velo corporativo para efecto de fijar límites de concentración en la inversión de los inversionistas institucionales, principalmente las AFPs, y no como causal para gatillar una OPA.

Por otra parte, el llamado poder de bloqueo de la tesis en comento, no es simplemente una cuestión de porcentajes de participación, según esta señala, sino que depende de variables tales como el precio de una acción y de posibilidades de financiamiento de oferentes potenciales. Por ejemplo, pensemos en una sociedad relativamente pequeña, sin presencia bursátil, con un valor libro bajo y con una propiedad altamente concentrada. Para un inversionista con capacidad de financiamiento es presumible que le será relativamente fácil presentar una oferta atrayente. Por el contrario, pensemos en una sociedad cuyo capital accionario se encuentra altamente disperso, con presencia bursátil, alto precio por acción y en que el mayor accionista cuenta con un $15 \%$ de las acciones, pudiendo nombrar, supongamos, 3 de 5 directores, sin que existan otros accionistas con más de un $0,5 \%$ de las acciones (sea 
individualmente o con acuerdo de actuación conjunta). Posiblemente no existirán muchos inversionistas capaces de alcanzar un porcentaje igual o superior al 15\%, teniendo en cuenta que este accionista mayoritario también puede realizar nuevas adquisiciones de acciones. De esta forma, quien pretenda tomar el control de la compañía deberá ser capaz de financiar la compra de tal un número de acciones que sean suficientes para superar al mencionado accionista, teniendo este, bajo estas circunstancias, suficiente poder de bloqueo frente a un posible intento de toma de control. Sobre la base de las constataciones descritas que constituyen una mera "muestra" de lo que pudiere acontecer en la compleja realidad de las sociedades anónimas es que la distinción entre control legal efectivo y control legal precario es incorrecta, por no asilarse en sustento empírico alguno.

\subsection{CONCEPTO ECLÉCTICO DE CONTROL}

Finalmente, hay autores que le dan a este concepto un carácter ecléctico, en el que coexisten dos formas de control: la primera basada en la propiedad y la segunda basada en la capacidad de coalición. Aquellos aceptan que existe una noción establecida en la LMV y, a la vez, concurre el término control como capacidad de gobernar o tomar las decisiones estratégicas dentro de la sociedad.

Se ha sostenido por esta posición que:

“... el artículo 203, letra a) de la misma ley, al tratar del contenido del prospecto donde consta la OPA, establece que él debe contener: ...una descripción financiera, jurídica y de los negocios del oferente o de sus controladores efectivos y finales, según fuere el caso... (el énfasis es del informante). Parece obvio, a la luz del precepto que se acaba de citar, que el control al que subordina la OPA puede ser un control efectivo y final". Agrega que un "somero análisis de las reglas precedentes, permiten alcanzar la siguiente y obvia conclusión: bajo la regla del artículo 199, letra c), la adquisición del control desencadena la obligatoriedad de una OPA. Ese control, a la luz de los requisitos del prospecto que enuncia el artículo 203, puede ser efectivo (concepto que la ley no define) o revestir la forma de un cambio de controlador bajo la regla del artículo 97, entendiéndose por tal quien tiene influencia decisiva en la administración de la sociedad cuyas acciones deberán ofertarse mediante una OPA. Prima facie, el cambio de controlador equivale a la adquisición del control, salvo los casos previstos en el artículo 99".

Según esta posición, las características que debe tener el control para ser causal de una OPA obligatoria son:

"Poder de coalición de un conjunto de personas o del nivel de propiedad que poseen, a fin de alinear al ente controlado con sus propios intereses. En otras palabras, y en prin- 
cipio, la capacidad de control depende de cualquiera de las dos siguientes variables, según lo enseña el derecho de sociedades y la teoría económica: Primero, del grado de propiedad que una persona tenga sobre el capital social y, en consecuencia, los flujos futuros... Segunda, del poder de coalición o, en otras palabras, de la facilidad que tenga un grupo de personas que individualmente no tiene el control, para asociarse, alcanzar acuerdos y así lograr la capacidad de gobierno"9.

Otro autor agregó que “... conviene consignar que más allá del concepto que explícitamente se recoja en la ley (por lo demás con contornos bastante imprecisos) aquella reconoce la posibilidad de tener un control de hecho, fáctico o efectivo sobre una sociedad anónima, el cual no coincide necesariamente con su propia definición del tema" ${ }^{10}$.

Esta definición ecléctica, si bien recoge de mejor manera la intrínseca complejidad de la temática en análisis, mantiene los defectos esbozados a propósito de la noción de hecho de control (incertidumbre) y del concepto de control como controlador (inconsistencia), las que damos por reproducidas íntegramente.

\section{ANÁLISIS DE LA JURISPRUDENCIA}

Según la jurisprudencia administrativa de la SVS y lo sentenciado por nuestros tribunales de justicia, la definición de control se corresponde plenamente con la definición legal de controlador del artículo 97 y siguientes de la LMV.

La SVS sostuvo al efecto que: "el control de una sociedad anónima sujeta a las normas de la ley 18.045, requiere del controlador la participación propietaria directa o indirecta en el capital accionario de la misma y que dicha participación sea tal que permita a su titular cualquiera de las siguientes actuaciones, a saber: a) controlar la mayoría de los votos en las juntas de accionistas y designar la mayoría de miembros del directorio, o b) ejercer influencia decisiva en la administración de la sociedad"11.

\footnotetext{
9 Peña GonzÁlez, Carlos. "Informe en Derecho sobre Oferta Pública de Adquisición de Acciones”, en: Revista de Derecho Privado Fernando Fueyo Laneri, vol. 1, pp. 233-237. Santiago, Chile: Fundación Fernando Fuego, Universidad Diego Portales, 2003.

10 A pesar de cierto aparente antagonismo entre las posiciones de los profesores Pfeffer y Alcalde, ellos coinciden en algo central, como es que el concepto de control es, sin duda, el concepto legal de controlador. Así, la genuina discusión entre ambos autores se enmarca solamente en torno al problema de si el concepto de controlador es exclusivamente el que dan los artículos 97 y siguientes, o si, por el contrario, la LMV acepta otro concepto de control.

ALCALDE, Enrique. "Regulación sobre la 'venta del control' en la ley de OPAS ¿̇un caso de iniquidad o simplemente un error?", en: Revista Chilena de Derecho, Vol. 28, pp. 599-614. Santiago, Chile: Pontificia Universidad Católica de Chile, 2001; ALCALDE, Enrique. La Sociedad Anónima. Santiago, Chile: Editorial Jurídica de Chile, 2007, pp.143-145.

11 Chile. Superintendencia de VAlores y Seguros. Oficio No 229, 18 noviembre 2004.
} 
Esta posición fue defendida en el denominado Caso Chispas $^{12}$. En dicha causa, la SVS sostuvo que el control efectivo de una compañía solo se "detenta" a partir de la propiedad directa o indirecta que se tiene de un número suficiente de acciones que permita asegurar la mayoría en la junta de accionistas y elegir a la mayoría de los miembros del directorio y que, como es de suponer, no es posible construir ni estructurar el concepto de controlador a partir de la confianza que los accionistas depositan en las personas al elegirlas como directores en una compañía.

Los llamados gestores clave argumentaron que eran titulares de un esquema de control sobre Enersis S.A., el que se basaba en parte por la propiedad de las acciones y en parte en la confianza de los demás accionistas. Los gestores claves eran dueños, según sus argumentos, de un bien de carácter patrimonial y susceptible de transferirse y enajenarse.

A mi juicio, la sentencia definitiva de la Excma. Corte Suprema no se refirió directamente al control corporativo, al contrario de lo que se ha señalado en torno a ella ${ }^{13}$.

Otro pronunciamiento significativo fue aquel verificado a propósito de la controversia iniciada con el Oficio Ordinario No. 2534 de la SVS ${ }^{14}$, con fecha de 14 de abril de $2003^{15}$. En dicho caso se discutió la obligatoriedad de una OPA en el caso de cambio de

12 "Mackenna E. Fernando Con Superintendencia de Valores y Seguros" (2005): Corte Suprema 7 julio de 2005 (Recurso de Casación en la Forma y Fondo).

13 Pfeffer, Francisco. "El concepto de control societario, la administración de la sociedad anónima, los conflictos de interés y la potestad punitiva de la Superintendencia de Valores y Seguros en el contexto del denominado 'Caso Chispas' ". <En línea> [consultado el 20 de diciembre de 2007] <http://www.pfeffer.cl/publicaciones/doc/EL\%20CONCEPTO\%20DE\%20CONTROL\%20SOCIETARIO.pdf>, p. 13. La Corte Suprema en sentencia del 8 de julio de 2005 afirma que: "no resulta cierto que se vulnere el derecho de dominio de los reclamantes, con relación a los paquetes accionarios de que eran dueños, pues en esa calidad podían disponer de ellos, tal como lo postulan. Sin embargo, ese acto de disposición se programó en el marco de un conjunto de acciones, que se adoptaron privilegiando sus propios intereses por sobre los de las sociedades a las que debían, al menos lealtad...”. Continúa dicha resolución "por otra parte, y en relación a lo argumentado, en orden a que no se ha podido sancionar a los reclamantes por haber actuado a título enteramente personal, se advierte lo contrario desde la perspectiva de los hechos sentados en el fallo que se revisa... en que se exponen las calidades que ostentan los reclamantes, y los contratos en que intervinieron, por lo que no resulta posible aceptar que los actores pudieran desdoblarse, abandonando sus calidades de Director o de Gerente que detentaban ... para actuar en los hechos reprochados únicamente como personas naturales, en ejercicio del derecho de dominio sobre sus paquetes accionarios...". En uno de sus considerando el fallo señala que "...la conducta omisiva que se reprocha (no haber informado) encuentra eco en la cláusula octava del contrato de gestión en que se convino guardar estricta reserva de todos los aspectos y materias contenidos en ese contrato...”. Así para la Corte Suprema el reproche por el que se sancionó a los gestores clave dice relación no con el derecho de dominio ni con la venta de acciones serie A y B de las sociedades Chispas, sino que con los compromisos de fiel colaboración que los sancionados asumieron en favor de Endesa, a fin de posibilitar que esta última, sirviéndose de la adhesión y confianza que todos los accionistas de Enersis y filiales habían depositado en los gestores clave, ejercieran, con la fiel colaboración de aquellos, en su provecho y beneficio, la influencia y poder de administración que emanaba de los cargos de directores y ejecutivos ocupados por los sancionados.

14 Para un resumen de los hechos en LAZÉn, Vicente y SEPÚlVEDA, Ana. "Desarrollo de las tomas de control corporativo en Chile después de la ley de OPAs". <En línea> [consultado el 28 de febrero] <http://www.svs.cl/sitio/publicaciones/doc/informe_serie_doc_trab4.pdf $>$, pp. 31-33.

15 "Anheuser Busch International Holdings Inc. Chile II Limitada con Superintendencia de Valores de Seguros" (2003): Corte de Apelaciones de Santiago 22 diciembre 2003 (Recurso de reclamación).

Dicho oficio en su considerando tercero señala que: "Cabe hacer presente que el Pacto opera a través del vehículo legal denominado IRSA, que es la sociedad controladora de CCU y regula las relaciones entre sus dos únicos socios. En IRSA, se convino una participación igualitaria del 50\% para cada accionista; asimismo, se estableció que se eligen los directores en forma paritaria 
uno de los miembros de la matriz, estando esta, su vez, controlada en partes iguales por sus dos únicos accionistas.

La Ilustrísima Corte de Apelaciones de Santiago en sentencia de 22 de diciembre de 2003, conociendo del recurso de reclamación deducido respecto del oficio ordinario antes individualizado, resolvió que la LMV no establece un concepto autónomo de control, ya que el artículo 97 de dicho texto legal establece que controlador de una sociedad anónima es toda persona o grupo de personas con acuerdo de actuación conjunta que, directa o indirectamente, participa en su propiedad y tiene poder para realizar alguna de las siguientes actuaciones: asegurar la mayoría de votos en las juntas de accionistas y elegir la mayoría de los directores, o influir decisivamente en la administración de la sociedad. Agrega que, si bien el vocablo control en nuestro idioma se le ha asimilado y se le utiliza ampliamente como dominio, mando, preponderancia, los conceptos controlar y controlador en sus únicas acepciones significan: ejercer el control y persona que controla respectivamente, es decir, los tres vocablos se refieren a una misma idea y entre ellos existe correspondencia y armonía. Finalmente concluyó que, pese a lo expuesto, el artículo 97 de la LMV establece una definición legal, por lo cual, de conformidad a lo establecido por el artículo 20 del Código Civil, debe estarse a esta. En consecuencia, siendo la LMV una norma que regula una materia especialísima, debe darse

y que, en el caso del Presidente del directorio este no tiene derecho a voto dirimente; así también acuerdan que tanto la presidencia como la vicepresidencia, en una ocasión nombre uno de los miembros del Pacto al presidente y el otro al vicepresidente, y convienen además que habrá una alternancia en el cargo. Conforme a la modificación del Pacto, Heineken ingresará a cambio de Paulaner, en las mismas condiciones y sin que se produzca una preponderancia de control de uno sobre otro en el Pacto; pero para lo anterior, las partes del Pacto han debido modificarlo específicamente para que pueda ingresar un tercero -Heineken-, en el plazo que se indica”. En el considerando cuarto agrega: “...Otro aspecto que debe considerarse, además de la norma recién transcrita son las disposiciones aplicables a los "controladores", y en especial, lo que prescriben los artículos 97 y 98 de la ley antes citada. Por una parte, el artículo 97 expresa que "Es controlador de una sociedad toda persona o grupo de personas con acuerdo de actuación conjunta que, directamente o a través de otras personas naturales o jurídicas, participa en su propiedad y tiene poder para realizar alguna de las siguientes actuaciones: a) Asegurar la mayoría de votos en las juntas de accionistas y elegir a la mayoría de los directores tratándose de sociedades anónimas, o asegurar la mayoría de votos en las asambleas o reuniones de sus miembros y designar al administrador o representante legal o a la mayoría de ellos, en otro tipo de sociedades, o b) Influir decisivamente en la administración de la sociedad. Cuando un grupo de personas tiene acuerdo de actuación conjunta para ejercer alguno de los poderes señalados en las letras anteriores, cada una de ellas se denominará miembro del controlador”. Según se desprende del Pacto, el vehículo de control de CCU es IRSA, que cuenta únicamente con dos accionistas Paulaner y Quiñenco, de lo que se deduce entonces que conforme al artículo 97, el controlador es un grupo de personas con acuerdo de actuación conjunta y como se trata de un grupo de personas, ellas son denominadas en forma individual por el legislador como "miembro del controlador". Finalmente señalaron que: "De acuerdo a la situación de la especie, es suficientemente claro que la transferencia de acciones de IRSA, en caso alguno permitirá a Heineken adquirir el control de este ni por consiguiente de CCU; por cuanto Heineken no podrá adquirir de Paulaner un control que este no tiene en IRSA, toda vez que ni Quiñenco ni Paulaner son capaces por sí solos de asegurar la mayoría de los votos en IRSA, de elegir a la mayoría de sus directores o de influir decisivamente en su administración, por las consideraciones legales que se ha hecho referencia más arriba por cuanto no existe un accionista controlador en IRSA y sí existen dos accionistas paritarios. Por ello que es improcedente aplicar la letra c) del artículo 199 porque esa norma se refiere a la adquisición del control y no al mero cambio de uno de los miembros del grupo controlador; sin perjuicio además, que esa disposición no impone la obligación de efectuar una OPA al adquirente de acciones de "un miembro del controlador" sino que solo al adquirente de las acciones del "controlador" y siempre que dicha adquisición le permita obtener precisamente el control directo o indirecto de la sociedad que hace oferta pública de sus acciones, situación en este caso que no se da, según hemos visto". 
al referido artículo 97 el significado y alcance que la ley ha querido, por lo cual, no es posible en el caso concreto hacer interpretaciones libres. En definitiva, la Corte equiparó control con la definición legal de controlador ${ }^{16}$.

De esta forma la SVS y los tribunales de justicia son consistentes en asimilar el concepto de control con el concepto de controlador del artículo 97 y 99 de la LMV, y en diferenciar entre controlador y miembro del grupo controlador, aseverando que no procede la aplicación obligatoria de una OPA en caso que exista cambio en un miembro del grupo controlador y el miembro entrante no es capaz, por sí solo, de ser controlador de la sociedad.

\section{CONCEPTO DE CONTROL APLICABLE AL ARTÍCULO 199 LETRA A) DE LA LMV}

Según fluye pacíficamente de las reglas elementales de interpretación establecidas en la legislación común y general, para que exista una definición que puede calificarse como "legal" se requiere que esta haya sido establecida explícitamente por el legislador y para materias específicas, condicionantes que no concurren de modo alguno respecto del concepto control ${ }^{17}$.

Incluso si consideramos la historia fidedigna del establecimiento de la ley, resulta diáfano que no estuvo en la intención del legislador societario definir expresamente la palabra control $^{18}$.

A mayor abundamiento, también debe tenerse presente que la definición legal de controlador fue establecida a propósito de la regulación de los grupos empresariales, debido a la creación de

“...un sistema de inversionistas institucionales, tanto por el lado de los fondos de pensiones -me estoy refiriendo a grandes inversionistas del país- como de las compañías de seguro, estableciendo normas de diversificación tendientes a que se expongan me-

\footnotetext{
16 Adicionalmente, en el Oficio Ordinario No 8991 de 29 de noviembre de 2002, la SVS señala que "Conforme a lo expuesto, a los antecedentes obtenidos por este Servicio y a los proporcionados por usted en su presentación, cabe señalar que no habría producido un cambio de control de la sociedad XX S.A., en el período indicado por usted, dado que las variaciones en las participaciones sociales en YY Limitada se habrían producido entre los miembros del controlador. Variaciones que no le permitirían a ningún miembro detentar el control por sí solo, sino que solo conjuntamente con el otro. Asimismo tampoco habría ingresado un nuevo miembro que pudiera hacer variar la composición del acuerdo de actuación conjunta". CHILE. SUPERINTENDENCIA DE VALORES Y SEguros. 2006, p. 259.

17 PeÑa GonZÁlez, Carlos, op. cit. (n. 9), p. 235.

18 La palabra control es definida expresamente en otras legislaciones. Por ejemplo, en la U.S. Securities Exchange Act de 1934, Rules $12 \mathrm{~B}$ control es definido como: "control is the term (including the term controlling, controlled by and under common control with) means the possession, direct or indirect, of the power to direct or cause the direction of the management and policies of a person, whether through the ownership of voting securities, by contract, or otherwise".
} 
nos al riesgo. Tratamos de decirles que no deben invertir en entidades con algún tipo de relación que las expongan más al riesgo" ${ }^{19}$.

Se agregó en el debate legislativo que los

“... objetivos básicos perseguidos con el proyecto en estudio son: a) entregar al mercado información que permita una mejor evaluación de los riesgos implícitos en la inversión en valores emitidos por entidades pertenecientes a un determinado grupo e emitidos por instituciones financieras comprometidas con ellas; b) reconocer, a través de la exigencia de información, los potenciales conflictos de interés que pueden presentar los negocios de las sociedades anónimas abiertas con sus personas relacionadas, con el objeto que los inversionistas puedan defender adecuadamente sus derechos a través de los mecanismos que les otorgan tanto el mercado como la legislación vigente, y c) entregar herramientas objetivas que permitan regular la diversificación mínima a que deben someterse algunos inversionistas institucionales que captan ahorros del público en general, específicamente de los fondos mutuos y las compañías de seguro" 20 .

Sobre la base de lo expuesto, se puede colegir que el objetivo principal para establecer las disposiciones tantas veces referidas, fue develar ciertos vínculos corporativos que eran difíciles de fiscalizar, y así se llegó a las definiciones de grupo empresarial, controlador, y acuerdo de actuación conjunta entre otros y no establecer, por cierto, un concepto de control para determinar la aplicación del procedimiento de $\mathrm{OPA}^{21}$.

En razón del vacío de definición legal de control, resulta perentorio para el intérprete realizar una interpretación sistemática de las disposiciones legales que regulan la materia, establecidas en la LMV y la LSA.

En la línea de desentrañar o, si se quiere, construir dicho concepto, cabe recordar que la LSA y su reglamento distinguen entre junta de accionistas, el directorio, los gerentes y, en algunos casos, el comité de directores, asignándole a cada uno de estos órganos un rol específico. No cabe duda que, conforme a la LSA, la administración de la sociedad anónima la ejerce un directorio elegido por la junta de accionistas, siendo la misma junta de accionistas la que tiene la facultad de nombrarlo y revocarlo en su totalidad.

\footnotetext{
19 Chile. Biblioteca del Congreso Nacional. Historia Fidedigna de la Ley No. 18.660 Ley de Mercado de Valores. Sesión conjunta de las comisiones legislativas en 30 de junio de 1987. Santiago, Chile, 1987, p. 1657.

20 Chile. Biblioteca del Congreso Nacional. Historia Fidedigna de la Ley No. 18.660 Ley de Mercado de Valores. Informe de Comisión Legislativa Conjunta, del 17 de agosto de 1987. Santiago, Chile,, 1987, p. 1867.

21 En el mismo sentido LuCO, Nicolás. "Protección a los accionistas minoritarios frente a la toma de control de una sociedad anónima abierta”, en: Revista Chilena de Derecho, Vol. 22 No 3. pp. 417-438, p.420. Santiago, Chile: Pontificia Universidad Católica de Chile, 1995.
} 
El directorio está investido, a su vez, de todas las facultades de administración y disposición que la ley o los estatutos no establezcan como privativas de la junta general de accionistas, sin que sea necesario otorgarle poder especial alguno.

Por otra parte, el gerente es un mandatario del directorio siendo nombrado, revocado y fijadas expresamente sus facultades por aquel órgano.

De esta forma, conforme a nuestro sistema legal, el poder decisorio predominante dentro de una compañía se encuentra situado en la junta de accionistas, ya que aquella toma las decisiones más importantes, entre ellas los aumentos y disminuciones de capital; fusiones; divisiones; enajenación de más del 50\% de los activos, disolución y, por cierto, elegir y remover el directorio. El directorio, por su parte, toma las decisiones de administración necesaria o conducentes a producir los flujos económicos de retorno de inversión para los accionistas, pero, para efectos legales, carecen de poder autónomo por sobre la junta de accionistas, por la mencionada facultad de remoción. De esta forma, la llave en las decisiones corporativas la tiene, en definitiva, el accionista (individualmente o mediante coalición) que tengan suficiente número de votos para remover y nombrar un directorio (sin importar el porcentaje de acciones que posean), siendo este el verdadero concepto de control que recoge nuestra legislación vigente.

Es por todo lo anterior que para que sea aplicable una OPA obligatoria no es suficiente adquirir acciones según los porcentajes de propiedad establecidos arbitrariamente por el artículo 99 de la LMV al definir influencia decisiva, sino que a su vez es necesario realizar un análisis ex ante en concreto referido a cada compañía particular, para determinar el número de acciones necesaria para que un accionista pueda nombrar y revocar al directorio, lo que dependerá, por cierto, de la concentración accionaria en cada caso particular.

\section{PREMIO DE CONTROL Y SU PROPIEDAD: ANÁLISIS CRÍTICO}

El llamado premio de control corresponde a la diferencia entre el precio de una acción que forma parte de un paquete controlador con otra acción de la misma sociedad que no forma parte de este.

Se ha sostenido que el premio de control se vincula a la capacidad de extracción de valor por parte de su titular debido a deficiencias regulatorias en materia de gobiernos corporativos $^{22}$

Se ha afirmado, incluso, que dicho premio es antijurídico, argumentando que en el caso de conflictos de interés dentro de la sociedad, como la voluntad corporativa se forma

22 DyCK, Alexander y ZiNGales, Luigi. Private Benefits of Control: An International Comparison. <En línea> [Consulta: 28 de febrero de 2010]. Disponible en World Wide Web:< http://papers.ssrn.com/sol3/papers.cfm?abstract_id=296107> 
por la voluntad de la mayoría, siempre estos conflictos tienden a resolverse en beneficio del controlador. Ello implicaría, se sostiene, privilegiar a este por sobre la sociedad y los otros accionistas, lo que es contrario al deber de respetar el interés de la sociedad y de los demás accionistas establecido del artículo 30 de la LSA, que a la letra señala: "Los accionistas deben ejercer sus derechos sociales respetando los de la sociedad y los de los demás accionistas". Continúa esta posición señalando que el pagar un valor superior por aquellas acciones que otorgan el control de una sociedad es ilícito ya que lo único que tendrían los controladores es el supuesto derecho a imponer sus decisiones sobre la voluntad de los demás accionistas, lo que es valioso únicamente cuando hay conflictos de interés, los que se resolverán a favor del controlador ${ }^{23}$.

Sin embargo, a mi juicio, la evidencia empírica antes referida, no justifica limitar de forma tan radical el derecho que tiene todo accionista de vender sus acciones al precio que acuerde libremente, obligando a este accionista a distribuir el premio por el control mediante la aplicación de procedimiento de OPA con regla de prorrateo.

Del mismo modo, el premio de control no es antijurídico porque el artículo 30 de la LSA establece que es un deber general de cuidado de los accionistas ejercer sus derechos sociales respetando los intereses de la sociedad y los de los demás los accionistas, deber que en sí mismo, y según lo expresamente estatuido en la disposición ya citada, no va más allá, ni encierra una exigencia concreta que permita alterar el régimen general de responsabilidad dispuesto en esta materia, más aún si con ello pretende derivarse una restricción -no expresamente regulada- a la libertad de cada accionista de fijar libremente el precio de sus acciones, limitante que en modo alguno guarda mínima correspondencia con los principios inspiradores del régimen societario chileno, y con las directrices básicas del orden público económico.

Por otra parte, como es de suponer, existen diferentes intereses legítimos dentro de una sociedad anónima, primando, en definitiva, aquel interés del o de los accionistas que representan, individualmente o conjuntamente, un mayor número de acciones, como es propio no solo dentro de una sociedad de capital. Lo anterior se fundamenta a su vez en que todo accionista que invierte en la sociedad, no tiene seguridad alguna de un retorno económico, el que se encuentra intrínsecamente unido al buen funcionamiento de la sociedad, decisiones de organismos regulatorios, decisiones de un tribunal, condiciones generales del mercado, y otras contingencias. La contrapartida de este riesgo son los derechos políticos y de monitoreo, como lo es el derecho a voto.

Por otra parte, el titular de control asume mayores riesgos que los accionistas minoritarios y, en consecuencia, tiene derecho a utilizar su derecho a voto en beneficio de sus intereses, que por lo demás -y según la simple lógica de subsistencia y mínima proyección- dichos

23 LyON, Alberto. Personas Jurídicas. Santiago, Chile: Ediciones Universidad Católica de Chile, 2006, pp. 287-290. 
intereses no pueden sino encontrarse alineados (sino en su totalidad, en gran parte) con el interés general de la sociedad, teniendo en vista el interés de protección de su propia inversión.

Adicionalmente, es necesario tener especialmente presente que existen disposiciones que limitan de manera importante las posibilidades de extracción de valor en una sociedad, limitando una posible conducta oportunista del titular de control. Evidencia concreta de lo señalado, lo constituyen las restricciones legales a los directores de una sociedad anónima para realizar operaciones en que el director tenga un interés personal o como representante de otra persona. Dichas operaciones, que deben ser aprobadas por el directorio, se deben ajustar a las condiciones de equidad que habitualmente prevalecen en el mercado. Existe, de esta forma, un límite formal que consiste en la aprobación de dicha operación por el directorio, y un límite material que consiste en que la operación se enmarque en condiciones de mercado.

Por otra parte, la mayoría de la literatura especializada ha identificado diversas motivaciones para realizar una OPA pagando en esta un premio de control y no prejuzga una intención de extracción de valor respecto de los accionistas minoritarios ${ }^{24}$. En general, los oferentes tienen la expectativa de obtener beneficios por la sinergia entre dos sociedades, es decir, de la combinación del valor y/o de las características de ambas sociedades de las cuales son titulares. Se ha demostrado que la principal motivación para tomar el control es administrar los activos de la sociedad de forma más eficiente, aumentando el precio de la acción. En este sentido, para el accionista entrante tiene más utilidad, en un sentido económico, adquirir las acciones que le dan el control. En cambio, para el accionista saliente es más valioso obtener flujos presentes a través de la venta de sus acciones que mantener las acciones en su poder.

De lo anterior se deriva la idea de definir a la utilidad como la cualidad que vuelve deseable a un bien, y de medir la utilidad en unidades abstractas, cuyo valor solo tiene un significado subjetivo. Le evidencia empírica sugiere que el valor de la nueva sociedad resulta mayor a la suma de ambas sociedades individualmente consideradas, por diferentes motivos, verbigracia: motivos financieros, operacionales, creación de nuevas oportunidades de negocios, etc. ${ }^{25}$.

Por todo lo anterior, el que se contemple un premio por el control no puede ser calificado antijurídico, pudiendo ser traspasado al precio de la acción en una venta de control. Sostener que el premio de control es antijurídico o ineficiente es solamente prejuzgar, establecer presunciones, sin amparo legal ni evidencia empírica contundente, a las motivaciones empresariales del titular del control, las cuales, como hemos señalado, son múltiples.

\footnotetext{
24 MASCAREÑAS, Iñigo. Manual de adquisiciones y fusiones de empresas. Madrid, España: Serie Mac Graw-Still de Management, Mc Graw, 1993.

25 RomAnO, Roberta. "A guide to takeover: theory, evidence and regulation", en: Yale Journal on Regulation, No. 9. Connecticut, Estados Unidos: Yale Law School, 1992.
} 
Por otra parte, bastante se ha discutido acerca de quien es el propietario de dicho premio, entre quienes se pronuncian se señala que el premio de control: a) pertenece a todos los accionistas y la sociedad y b) pertenece al controlador saliente.

Se considera razonable que el titular de control saliente sea propietario del premio de control porque, el titular del control incurre en costos de monitoreo de la administración de la sociedad lo que optimiza la simetría de intereses entre los accionistas y la administración. Si tales actividades son ejecutadas por el controlador ello debe ser reflejado en el precio que retribuya dicha gestión.

También es fundamental para la obtención de financiamiento el prestigio y el know how que aporta el titular del control, es decir, no es indiferente para el mercado quién tiene la titularidad del control de una sociedad para efectos de financiamiento (en Chile principalmente a través de títulos de deuda).

Finalmente, la concentración de la propiedad no es gratuita. Para que la propiedad esté concentrada debe haber pocos propietarios dispuestos a arriesgar una fracción importante de su riqueza en una sola empresa. Por el contrario, los accionistas diversificados reducen su riesgo. Ese mayor riesgo que asume el controlador tiene un valor y es lícito y legítimo que sea transado en el mercado beneficiando exclusivamente al propietario de dicha valor.

\section{OPA OBLIGATORIA EN CHILE: UNA REVISIÓN}

El poder ejecutivo ${ }^{26}$ buscó con el entonces proyecto de ley sobre OPA, eliminar la posibilidad de una conducta oportunista por parte de la administración respecto de los propietarios o por parte de quien tiene el control respecto de los accionistas minoritarios, teniendo a la vista el traumático caso Chispas.

$\mathrm{Al}$ respecto, en la discusión legislativa, se sostuvo que existen dos reglas de transferencia de control, a saber: (a) la regla de mercado y (b) la regla de la igualdad de condiciones.

La regla de mercado permite que la venta de un paquete controlador y su precio es determinado en una negociación privada entre quien tiene el control y el oferente, sin participación alguna de los accionistas minoritarios. Bajo estas reglas se pueden dar las siguientes hipótesis: (a) Si la eficiencia del controlador entrante es mayor y su capacidad de extraer valor es igual, la transacción se realizará y los minoritarios se verán favorecidos. (b) Si la eficiencia del controlador entrante y su capacidad de extraer valor son mayores la transacción se llevará a cabo pero el resultado para los minoritarios será incierto ya que dependerá de las magnitudes de cada variable. (c) Si la eficiencia del controlador entrante es menor y la capacidad

26 Clarke, Álvaro. Modernización del mercado de capitales chileno: la nueva ley de ofertas públicas de adquisición de acciones y gobiernos corporativos. Serie Documentos de Discusión. Santiago, Chile: Superintendencia de Valores y Seguros, Chile, 2000 , p. 19. 
de extraer valor es mayor, se efectuará la transacción pero el resultado será perjudicial para los minoritarios. (d) Si la eficiencia del controlador entrante es mayor y la capacidad de extracción de valor es menor, la ejecución de la operación es incierta y en caso que se ejecute el resultado es beneficioso para los minoritarios. La regla de mercado permite que los accionistas minoritarios no sean considerados y pueden ejecutarse transacciones que puedan ser perjudiciales para sus intereses. La regla de mercado, sostiene, maximiza solo los intereses del controlador saliente.

Por el contrario, la regla de igualdad de condiciones, se sostiene, obliga a llamar a una OPA cada vez que se venda un paquete controlador. De esta forma, el oferente otorga a los accionistas minoritarios condiciones equivalentes a las del controlador saliente, reconociendo que también imposibilita operaciones a pesar de ser eficientes, puesto que el oferente no logra pagarle al controlador la extracción de valor que este realiza. Se señala que la regla de igualdad impide que se extraiga valor a los accionistas minoritarios pero no permite per se mejorar su situación ${ }^{27}$.

El mejor sistema, afirmó esta posición, es aquel que combina ambas reglas (regla mixta). Se obliga a tomar el control a través de una OPA en el caso que el premio de control sea sustancialmente mayor al precio de mercado. Finalmente, se señaló que existe una regla híbrida que participa de las características de las dos reglas antes descrita. Cuando el premio de control es "sustancialmente mayor al de mercado" no se permite la transacción privada.

En mi opinión, la obligatoriedad de realizar una OPA, según esta regla híbrida, con una regla de prorrateo carece de justificación ${ }^{28}$ por las siguientes razones:

(a) Se ha demostrado que existe una relación entre concentración accionaria, riqueza y distribución de esa riqueza ${ }^{29}$. El control de una sociedad depende tanto de la distribución de la riqueza en la economía en general y el tiempo y habilidades con que cuenten los inversionistas. El riesgo inherente a la obtención de una fracción controladora es reflejo de la riqueza del accionista y del tiempo y conocimientos de que dispone. La desigualdad en la distribución de la riqueza posibilita que una cantidad de riqueza se logre y en consecuencia permite adquirir el control de una sociedad a través de la propiedad de las acciones, por lo que el establecimiento de una OPA obligatoria no ayuda a lograr mayor liquidez y profundidad en el mercado de valores en Chile.

\footnotetext{
BEBCHUK, Lucian. "Efficient and inefficient sales of Corporate Control", en: Quarterly Journal of Economics, vol. 109, pp. 957-993. Massachussetts, Estados Unidos: Harvard University, 1994.

28 La presente crítica se refiere exclusivamente a la inconveniencia de una regla de prorrateo establecido en el procedimiento de OPA y no a los deberes de información en los cuales se deben enmarcar las adquisiciones de acciones con este procedimiento. Por ello considero razonable y adecuado la exigencia de amplios y detallados deberes de información dentro de los procesos de tomas de control, sea o no en aplicación de una OPA.

29 DEMSETZ, Harold. "Control empresarial, riqueza y desarrollo económico", en: Revista de Estudios Públicos, vol. 58, pp. 197226. Santiago, Chile: Centro de Estudios Públicos, 1995.
} 
(b) Hay que tener en consideración, además, las diversas formas de estructura de financiamiento en las economías, que inciden, por cierto, directamente en el control corporativo, a saber: 1) sistemas orientados hacia el mercado y 2) sistemas orientados hacia la banca ${ }^{30}$. Estos modelos no son de espontáneo surgimiento sino que derivan de una legislación que ha favorecido el crecimiento de uno u otro mercado.

En el caso de EE.UU., la legislación influyó en la relación que existe entre mercado bancario y mercado de valores, inhibiendo el crecimiento del primero y favoreciendo que los excedentes de la economía se invirtieran en el segundo ${ }^{31}$. Esta política legislativa indujo a que el mercado bancario sea relativamente pequeño y fragmentado lo cual orientó las posibilidades de financiamiento a través del mercado de valores de oferta pública con la emisión de títulos de propiedad (acciones) y títulos de deuda (principalmente bonos) que fueron adquiridos por el público inversionista. Por la mayor profundidad y liquidez del mercado norteamericano el mercado de control corporativo es un mecanismo de vigilancia de la mala administración, ya que aquella es removida de sus cargos por medio de tomas de control hostil, en que un inversionista identificó a la administración como causa de la subvaloración de las acciones. En consecuencia, el mercado de control corporativo en este tipo de sistema tiene gran importancia por el efecto disciplinador o represivo y un efecto preventivo respecto de la administración de las sociedades. No obstante, en EE.UU. la OPA, al menos en su legislación federal, es de carácter voluntario.

Por otra parte, el sistema orientado hacia la banca se caracteriza por tener un mercado de valores menos profundo y en que la principal forma de financiamiento es a través del mercado bancario. La mayor centralización en el sistema financiero determina la mayor concentración en la propiedad de las sociedades, como lo es el caso alemán ${ }^{32}$.

30 Guerra, Guillermo. El Gobierno de las Sociedades Cotizadas Estadounidenses. Su influencia en el movimiento de reforma del Derecho europeo. Madrid, España: Editorial Aranzadi, 2003, p. 107.

31 Así a partir del siglo XIX la legislación norteamericana fue restrictiva respecto de las posibilidades de crecimiento de los bancos y limitativo de sus posibilidades de inversión en acciones. En un comienzo cada Estado excluyó el establecimiento de sucursales de bancos constituidos en otros estados y, en consecuencia, los bancos tuvieron un tamaño muy reducido cuya área de actividad era una ciudad. Las limitaciones a su crecimiento geográfico se restringieron el ámbito de sus actividades a través de la National Bank Act de 1863 y 1864. Esta política restrictiva respecto del mercado bancario fue ratificada por la Suprema Corte de los EEUU, que dictaminó que en el caso de no estar autorizados expresamente por la National Bank Act le estaba prohibido a los bancos invertir en acciones de sociedades. De esta forma se separa tajantemente la actividad bancaria de la actividad de inversión. Con la Banking Act de 1933 se prohibió a las filiales de los bancos la propiedad de valores de oferta pública. La Bank Holding Company Act de 1959 prohibió la adquisición de una sociedad no bancaria sea directa o indirectamente.

32 LEVINE, Ross. "¿Son mejores los sistemas financieros basados en el sistema bancario o los basados en el Mercado bursátil?", en: Revista de Economía, vol. 3, No. 1, p. 32. Santiago, Chile: Banco Central de Chile, 2000 ; Guerra, Guillermo, op. cit. (n. 30), pp. 108-111. En estos países la legislación fomentó la concentración de capitales en los bancos y su participación activa en la propiedad de la industria. En Europa Continental la Banca Alemana participa activamente en la administración de las sociedades. Por ejemplo, en 1992 los administradores bancarios ejercieron en promedio $61 \%$ de los derechos a voto de las 24 compañías más grandes y en 11 compañías esta porción fue mayor que 75\%. Este control de las corporaciones por parte de la administración de los bancos se extiende a los mismos bancos. Por ejemplo, Deutsche Bank mantenía derechos de votación por $47 \%$ de sus propias acciones, mientras que Dresdner vota $59 \%$ de sus propias acciones. Entonces, la administración del banco ejerce una gran influencia sobre las mayores corporaciones del país. 
En Chile, la evidencia empírica disponible sugiere que la mayoría de las operaciones de toma de control han sido amistosas. Lo anterior se explica por las características que tiene el mercado chileno, el que se asimila al sistema orientado hacia la banca. En Chile los montos transados corresponden en promedio al $10 \%$ del patrimonio bursátil, es decir, solo el 10\% de la propiedad de las sociedades en bolsa cambia de dueños. En contraste, en EE.UU. la rotación accionaria equivale al $90 \%$ al año. Ello refleja que el mercado accionario chileno es altamente concentrado ${ }^{33}$. En promedio el accionista mayoritario -en sentido de cantidad de acciones y no en sentido legal- es dueño del 50\% de las acciones. El segundo accionista es dueño de poco más del 10\% de las acciones, en consecuencia, no puede bloquear las decisiones del controlador. Pero las decisiones que requieren quórum calificado el controlador requeriría de la colaboración de los tres mayores accionistas. Como consecuencia de lo anterior, el mercado de control corporativo en nuestro país no es un mecanismo externo de disciplina de la administración ineficiente porque las sociedades son controladas por el accionista mayoritario y para adquirir el control de la sociedad necesariamente se requiere la colaboración del titular del control y la administración. Esto indicaría que el motivo principal de las tomas de control en nuestro país ha sido la búsqueda de sinergia, economías de escala, o crecimiento en el mercado. Se puede colegir que este mercado en Chile se acerca al modelo orientado hacia la banca $Y$, en consecuencia, la obligatoriedad de una OPA no es significativa para fomentar la profundidad del mercado de valores.

(c) No existe conexión demostrada entre el valor por el control con una posible conducta oportunista de controlador entrante. La conducta oportunista del controlador y la administración se pueden limitar por la regulación que sancione ex post dicha conducta. Asimismo, el propio mercado sanciona a los controladores o administradores que incurren en conductas oportunistas (expropiación de valor de los minoritarios) por medio de asignarle un menor valor bursátil a sus acciones y un fuerte deterioro en la imagen del controlador y la administración. "los controladores que expropian valor a los accionistas minoritarios, se hacen a la larga el harakiri, ya que no solo destruyen valor de terceros sino que también el propio, además de limitar su capacidad de levantar financiamiento accionario a futuro" 34 . Desde la perspectiva de la teoría de juegos, nos encontramos en un juego extensivo o de jugada múltiple $^{35}$. Bajo este tipo de juego, las decisiones que toman los participantes tienen repercusiones en el siguiente juego o nivel. Entonces, una decisión tomada en el nivel uno, tendrá efectos positivos o negativos en el nivel 2, y luego el nivel 3, y así sucesivamente. Llevándolo a la

33 Álvarez, Carola y RaINERI Ricardo. Mercado de Control Corporativo en Chile. <En línea> [citado el 28 febrero de 2008] <http://www.ricardoraineri.cl/Papers/RaineriAlvarez.pdf>, p. 8.

34 PaUl, Luis Hernán. Regulación del Mercado de Control de Empresas. <En línea> [consultado el 28 de febrero de 2008] <www.cepchile.cl/dms/archivo_1926_1446/pder214_paul.pdf>, p. 4.

35 Baird, Douglas G., GerTner, Robert H., y PICKER, Randal C. Game Theory and the Law. Massachussets, Estados Unidos: Harvard University Press, 1994, p. 50. 
materia que nos ocupa, un accionista que tome el control perjudicando a los minoritarios debería ser sancionado por el mercado y en el futuro existirá merma en el prestigio del controlador y no podrá, probablemente, levantar financiamiento para nuevos proyectos.

(d) Un mercado eficiente donde las partes actúan libremente, cada una de ellas debe internalizar los costos y beneficios. Las externalidades son fallas de mercado y ocurre cuando los costos y los beneficios no son internalizados los agentes que participan en el mercado. Así, la administración por parte del titular del control crea externalidades ya que los accionistas minoritarios captan los beneficios de la administración sin asumir ningún costo de dicha administración. Así el premio de control viene a corregir dicha falla de mercado.

(e) En un mercado donde existan personas que son titulares del control, estas solo lo transferirán si el oferente está dispuesto a pagar el valor de control ya que para el controlador es irrelevante el costo total del oferente. Por ello en el caso que exista una obligación de realizar una OPA en un mercado concentrado -como el chileno- el único efecto relevante es la elevación de los costos del oferente para obtener el control de una sociedad y, en consecuencia, desincentiva toda toma de control.

(f) Finalmente, la evidencia empírica disponible 36 sugiere que el hecho que algunas empresas se hayan acogido al artículo $10^{\circ}$ transitorio (es decir, en general, no someterse a las disposiciones referidas a OPA de carácter obligatorio) no parece haber sido considerado relevante por el mercado chileno. Una razón para ello, concluye dicho estudio, podría ser la alta concentración de la propiedad de las empresas. El que las empresas se hayan acogido a este artículo podría ser una mala señal para aquellos inversionistas que no poseen el control, pero dada su baja participación en la propiedad, esto no se ve reflejado en los precios accionarios. Igualmente concluye que en el caso de las empresas no acogidas a dicha disposición presentaron, en la mayoría de los casos, excesos de retorno no significativos estadísticamente, es decir, tampoco hubo un efecto importante en el caso de los precios de estas acciones. En consecuencia, el mercado accionario chileno no considera relevante el anuncio de acogerse $-\mathrm{O}$ no hacerlo- al artículo $10^{\circ}$ transitorio de la Ley No. 19.705.

Sobre la base de todo lo anterior, parece razonable concluir que el mecanismo adecuado para resolver los problemas de conducta oportunista de un accionista controlador son las acciones de indemnización por perjuicios y no el establecimiento de un deber particular al accionista controlador de enajenar sus acciones sujeto a una regla de prorrateo como la establecida en la LMV. Así, lege ferenda no debería existir entorpecimientos legales a la libre cesibilidad de las acciones.

36 CONCHA, Danilo y Videla, Manuel. Sociedades Anónimas acogidas al artículo $10^{\circ}$ transitorio de la ley de OPAS y su efecto en los precios accionarios. <En linea> [consultado el 28 febrero de 2008] <http://www.cybertesis.cl/tesis/uchile/2003/ concha_d/sources/concha_d.pdf $>$, p. 40. 


\section{CONCLUSIONES}

7.1. Desde la perspectiva jurídica, la certeza es uno de los principios más relevantes de todo ordenamiento. Es por ello que es indispensable que el concepto de control se base en criterios normativos.

7.2. El mercado chileno se asimila a los sistemas orientados hacia la banca, y por ello la gran mayoría de las operaciones de toma de control en Chile han sido amistosas, generalmente a través de transacciones privadas. Como consecuencia de lo anterior, el mercado de control corporativo en nuestro país no es un mecanismo externo de disciplina de la administración ineficiente porque, primero, las sociedades son controladas por el accionista mayoritario y, segundo, para adquirir el control de la sociedad necesariamente se requiere la colaboración de la administración. Esto indicaría que el motivo principal de las tomas de control en nuestro país ha sido la búsqueda de sinergia, economías de escala, o crecimiento en el mercado.

7.3. Para el controlador es irrelevante el costo total del oferente para adquirir el control de una compañía. Por ello en el caso que exista una obligación de realizar una OPA obligatoria en un mercado concentrado -como lo es el chileno- el único efecto relevante es la elevación de los costos para el oferente para obtener el control de una sociedad y, en consecuencia, desincentivando toda toma de control.

7.4. De esta forma, no se logran los fines señalados por el ejecutivo de aquella época al presentar estas modificaciones legales. En definitiva, es indispensable la liberalización de este procedimiento transformándolo en facultativo.

\section{REFERENCIAS BIBLIOGRÁFICAS}

AlCALDE, Enrique. "Regulación sobre la 'venta del control' en la ley de OPAS. ¿Un caso de iniquidad o simplemente un error?”, en: Revista Chilena de Derecho, Vol. 28. Santiago, Chile: Pontificia Universidad Católica de Chile, 2001.

. La Sociedad Anónima. Santiago, Chile: Editorial Jurídica de Chile, 2007.

Álvarez, Carola y RAINERI Ricardo. Mercado de Control Corporativo en Chile. <En línea> [citado el 28 febrero de 2008]. Disponible en World Wide Web: <http://www.ricardoraineri.cl/Papers/RaineriAlvarez.pdf>

BAIRD, Douglas G., et al. Game Theory and the Law. Massachusetts, Estados Unidos: Harvard University Press, 1994.

BEBCHUK, Lucian. "Efficient and inefficient sales of Corporate Control”, en: Quarterly Journal of Economics, vol. 109, 1994.

CABrera, Ángel; et al. Regulación de las transferencias de control corporativo: Discusión teórica e implementación empírica. Santiago, Chile: Serie Documentos de Discusión. Superintendencia de Valores y Seguros, 2000.

Chile. Biblioteca del Congreso Nacional. Historia Fidedigna de la Ley No. 18.660 Ley de Mercado de Valores. Sesión conjunta de las comisiones legislativas en 30 de junio de 1987. Santiago, Chile, 1987. 
Historia Fidedigna de la Ley No. 18.660 Ley de Mercado de Valores. Informe de Comisión Legislativa Conjunta, del 17 de agosto de 1987. Santiago, Chile, 1987.

Historia Fidedigna de la Ley No 19.705, que Regula las Ofertas Públicas de Adquisición de Acciones (OPAS) y Establece Régimen de Gobiernos Corporativos. Santiago, Chile, 1987.

Chile. Superintendencia de Valores y Seguros. Dictámenes Mercado Valores 2000-2004. Santiago, Chile, 2006.

ClARKe, Álvaro. Modernización del mercado de capitales chileno: la nueva ley de ofertas públicas de adquisición de acciones y gobiernos corporativos. Serie Documentos de Discusión. Santiago, Chile: Superintendencia de Valores y Seguros, 2000.

COnCHA, Danilo y VIDEla, Manuel. Sociedades Anónimas acogidas al artículo $10^{\circ}$ transitorio de la ley de OPAS y su efecto en los precios accionarios. <En línea> [consultado el 28 febrero de 2008]. Disponible en World Wide Web: <http://www.cybertesis.cl/tesis/uchile/2003/concha_d/sources/concha_d.pdf>

DemSETZ, Harold. "Control empresarial, riqueza y desarrollo económico”, en: Revista de Estudios Públicos, vol. 58. Santiago, Chile: Centro de Estudios Públicos, 1995.

DyCK, Alexander y ZINGALES, Luigi. Private Benefits of Control: An International Comparison. 2001. <En línea> [Consulta: 28 de febrero de 2010]. Disponible en World Wide Web:<http://papers.ssrn.com/sol3/papers. cfm?abstract_id=296107>

GUERRA, Guillermo. El Gobierno de las Sociedades Cotizadas Estadounidenses. Su influencia en el movimiento de reforma del Derecho europeo. Madrid, España: Editorial Aranzadi, 2003.

Jensen, Michael y Mecking, Williams. "Theory of the Firm: Managerial Behaviour, Agency Cost and Ownership Structure”, en: Journal of Financial Economics, vol. 3, 1976.

LAZÉn, Vicente y SEPÚlVEdA, Ana. Desarrollo de las tomas de control corporativo en Chile después de la ley de OPAs. 2004<En línea> [consultado el 28 de febrero de 2010]. Disponible en World Wide Web: <http:// www.svs.cl/sitio/publicaciones/doc/informe_serie_doc_trab4.pdf>

LEVINE, Ross. "¿Son mejores los sistemas financieros basados en el sistema bancario o los basados en el Mercado bursátil?”, en: Revista de Economia, vol. 3, No. 1. Santiago, Chile: Banco Central de Chile, 2000.

LYON, Alberto. Personas Jurídicas. Santiago, Chile: Ediciones Universidad Católica de Chile, 2006.

LUCO, Nicolás. "Protección a los accionistas minoritarios frente a la toma de control de una sociedad anónima abierta”, en: Revista Chilena de Derecho. Vol. 22 No 3. Santiago, Chile: Pontificia Universidad Católica de Chile, 1995.

MASCAREÑAS, Iñigo. Manual de adquisiciones y fusiones de empresas. Madrid, España: Serie Mac Graw-Still de Management, Mc Graw, 1993.

PeÑa GonZÁlez, Carlos. "Informe en Derecho sobre Oferta Pública de Adquisición de Acciones”, en: Revista Chilena de Derecho Privado, Fernando Fueyo Laneri, vol. 1. Santiago, Chile: Fundación Fernando Fueyo, Universidad Diego Portales, 2003.

PAUL, Luis Hernán. Regulación del Mercado de Control de Empresas. <En línea> [consultado el 28 de febrero de 2008]. Disponible en World Wide Web: <www.cepchile.cl/dms/archivo_1926_1446/pder214_paul.pdf>

PFEFFER, Francisco. "Nuevas regulaciones en las tomas de control y oferta pública de adquisición de acciones", en: Revista Chilena de Derecho, vol. 28, No 1, Santiago, Chile: Pontificia Universidad Católica de Chile, 2001.

"El concepto de control societario, la administración de la sociedad anónima, los conflictos de interés y la potestad punitiva de la Superintendencia de Valores y Seguros en el contexto del denominado “Caso Chispas'”. <En línea> [consultado el 20 de diciembre de 2007]. Disponible en World Wide Web: $<$ http://www.pfeffer.cl/publicaciones/doc/EL\%20CONCEPTO\%20DE\%20CONTROL\%20SOCIETARIO.pdf>

"El concepto de control societario, la administración de la sociedad anónima, los conflictos de interés y la potestad punitiva de la Superintendencia de Valores y Seguros en el contexto del denominado 
“Caso Chispas", en: Revista Chilena de Derecho, vol. 32, No. 3, Santiago, Chile: Pontificia Universidad Católica de Chile, 2005.

ROMANO, Roberta. "A guide to takeover: theory, evidence and regulation”, en: Yale Journal on Regulation, No. 9. Connecticut, Estados Unidos: Yale Law School, 1992.

VIAL, Felipe. "Responsabilidad civil extracontractual del controlador de sociedades", en: Revista de Derecho Económico, No. 68-69. Santiago, Chile: Departamento de Derecho Económico, Facultad de Derecho Universidad de Chile, 1987.

\section{NORMAS LEGALES}

Ley No. 18.045, Ley de Mercado de Valores. Diario Oficial, 22 de octubre de 1981.

Ley No. 18.046, Ley de Sociedades Anónimas. Diario Oficial, 22 de octubre de 1981.

Decreto Ley No. 3.500, Establece Nuevo Sistema de Pensiones. Diario Oficial, 13 de noviembre de 1980.

U.S. Securities Exchange Act of 1934 Rules 12B.

\section{JURISPRUDENCIA CITADA}

"Anheuser Busch International Holdings Inc. Chile II Limitada con Superintendencia De VAlores De Seguros" (2003): Corte de Apelaciones de Santiago 22 diciembre 2003 (Recurso de reclamación).

“Mackenna E, Fernando Con Superintendencia de Valores y Seguros” (2005): Corte Suprema 7 julio de 2005 (Recurso de Casación en la Forma y Fondo).

Chile. Superintendencia de VAlores y Seguros, Oficio No 229 del 18 noviembre 2004.

Oficio Ordinario No 02534 de 14 de abril de 2003.

Oficio Ordinario $N^{\circ} 8991$ de 29 de noviembre de 2002 